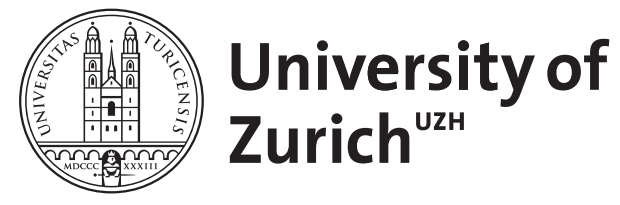
Archive

University of Zurich

University Library

Strickhofstrasse 39

CH-8057 Zurich

www.zora.uzh.ch

Year: 2016

\title{
Killing the Pain and Battling the Lethargy: Misleading Military Metaphors
} in Palliative Care

\author{
Trachsel, Manuel
}

DOI: https://doi.org/10.1080/15265161.2016.1214310

Posted at the Zurich Open Repository and Archive, University of Zurich ZORA URL: https://doi.org/10.5167/uzh-127946

Journal Article

Accepted Version

Originally published at:

Trachsel, Manuel (2016). Killing the Pain and Battling the Lethargy: Misleading Military Metaphors in Palliative Care. The American Journal of Bioethics, 16(10):24-25.

DOI: https://doi.org/10.1080/15265161.2016.1214310 
Open Peer Commentary

Target article: "Healing without Waging War: Beyond Military Metaphors in Medicine and HIV Cure Research"

\section{Killing the Pain and Battling the Lethargy: Misleading Military Metaphors in Palliative Care}

\section{Manuel Trachsel}

Jing-Bao Nie and colleagues (2016) show that military metaphors are pervasive in almost every branch of biomedicine research and practice, including and especially in HIV and cancer cure research. I agree that such language may be highly problematic when used within curative medicine. Over and above, I will argue that, beyond curative medicine, military metaphors are common even in palliative care, and that such violent language is still more problematic in this field of medicine.

Specifically, the language of palliative care speaks of "painkillers" (rather than analgesics or pain relievers), "killing the pain" (rather than pain alleviation), "battling lethargy" (rather than easing lethargy), "fighting insomnia" (rather than facilitating sleep and sleeping through), and "combating fatigue" (rather than making fatigue more bearable) (Davis and Goforth 2014; Gebauer, Hoopes and Finley 2013; Hamilton 1998; Olthuis and Dekkers 2003; Petrovich, Baert, and Brady 2012). This military vocabulary can be found even in the titles of scientific articles in internationally renowned and high-impact journals; examples include "Palliative Care in Amyotrophic Lateral Sclerosis: A new tool in the fight against an old enemy" (Baumrucker 2001); "From the battlefield to the palliative care arsenal" (Gebauer, Hoopes and Finley 2013); and "Fighting insomnia and battling lethargy" (Davis and Goforth 2014). This kind of military vocabulary is even more misleading in the context of palliative care, where the main goal is not to cure disease but to stabilize or improve quality of life and wellbeing without necessarily modifying disease progression. Rather than curing or healing, palliative care is

an approach that improves the quality of life of patients and their families facing the problem associated with life-threatening illness, through the prevention and relief of suffering by means of early identification and impeccable assessment and treatment of pain and other problems, physical, psychosocial and spiritual. (WHO 2014, n.p.)

A further characteristic of palliative care is the acceptance that certain burdensome symptoms cannot be completely alleviated, and that the process of dying entails a certain quantum of symptom load until death. However, symptom severity and perceived suffering are not identical. Patients can learn to reduce overall suffering through acceptance of their symptoms, using for example the Acceptance and Commitment Therapy model of psychotherapy also in the palliative care context (ACT; e.g., Rost et al. 2012). Clearly, the concept of acceptance is diametrically opposed to the concepts of killing, battling, defeating, or eliminating.

As Nie and colleagues (2016) emphasized, military metaphors can disproportionately intensify patients' awareness of the biomedical model of medicine. This may in turn lead to minimization or neglect of the other crucial aspects of palliative care: the psychological, 
social, and spiritual dimensions of suffering. Of course, relief of physical symptoms like pain, fatigue, dyspnea, loss of appetite, thirst, nausea, or vomiting is of central importance in palliative care. Of equal importance, however, is the reduction of psychological, social, and spiritual suffering, acknowledging and supporting coping with feelings of depression, anxiety, or delirium, as well as existential concerns such as death, finiteness, meaning, guilt, dignity, and isolation (e.g., Bolmsjö 2000). In short, the purpose of palliative care is the prevention and relief of all kinds of suffering.

This brief explication of palliative care highlights how absurd, grotesque, and undignified is the application of military metaphors to end-of-life or dying patients. Given these patients' particular vulnerability, it is an ethical duty of palliative care - even more than of curative medicine - to employ reasonable, respectful, and dignified language. In this context, it is more appropriate to speak about alleviating and reducing symptoms, disburdening patients, or fostering wellbeing. And because the careful choice of appropriate, respectful, mindful, and peaceful language may contribute to wellbeing at the end of life, palliative care stakeholders must formulate guidelines for practitioners that explicitly reject the use of inappropriate and violent military metaphors.

\section{References}

Baumrucker, S. J. 2001. Palliative care in Amyotrophic Lateral Sclerosis: a new tool in the fight against an old enemy. American Journal of Hospice \& Palliative Care 18(2): 8182.

Bolmsjö, I. 2000. Existential issues in palliative care-interviews with cancer patients. Journal of Palliative Care 16(2): 20-24.

Davis, M.P., and H. Goforth. 2014. Fighting insomnia and battling lethargy: the yin and yang of palliative care. Current Oncology Reports 16(377): 1-18.

Gebauer, S., Hoopes, D., and E. Finley. 2013. From the battlefield to the palliative care arsenal: application of QuickClot $\left(\right.$ C Combat Gauze ${ }^{\mathrm{TM}}$ for aggressive palliation of hemorrhagic shock in the setting of end-stage liver disease-associated compartment syndrome. Journal of Pain and Symptom Management 46(4): e6-8.

Hamilton, J. 1998. Music another weapon in palliative care arsenal. Canadian Medical Association Journal 158(10): 1260.

Olthuis, G., and W. Dekkers. 2003. Medical education, palliative care and moral attitude: some objectives and future perspectives. Medical Education 37: 928-933.

Nie, J. et al. 2016. Healing without waging war: beyond military metaphors in medicine and HIV cure research. American Journal of Bioethics x(x): xx-xx.

Petrovich, Z., L. Baert, and L. W. Brady. 2012. Carcinoma of the Bladder: Innovations in Management. Heidelberg: Springer Science \& Business Media.

Rost, A. D., K. Wilson, E. Buchanan et al. 2012. Improving psychological adjustment among late-stage ovarian cancer patients: examining the role of avoidance in treatment.

Cognitive and Behavioral Practice 19: 508-517.

World Health Organization (WHO). 2014. WHO definition of palliative care. Available at: www.who.int/cancer/palliative/definition/en (last accessed 15 June, 2016). 